\title{
Part One Summary: Adapting Warnings for Volcanic Hazards
}

\author{
William J. McGuire and Carina J. Fearnley
}

Of all the geophysical threats, volcanic activity is unique in having a particularly large and diverse portfolio of associated phenomena capable of causing death and injury, societal and economic disruption and damage to population centres and attendant infrastructure. Potentially hazardous phenomena as wide-ranging as ash, noxious gases, lava flows, pyroclastic density currents and tsunamis differ in terms of nature, predictability, scale, extent, impact and perception. As such, a 'one size fits all' approach does not provide the most effective means of addressing the communication of volcanic hazards, and while general principles apply, warnings that seek to manage and mitigate the effects of individual hazardous phenomena need to be adapted or tailored.

The chapters that form Part One of this volume demonstrate how this approach may be utilised successfully to tackle a variety of specific hazards, ranging from those that apply in the immediate vicinity of a volcano, notably ballistic ejecta, hydrothermal events, and pyroclastic density currents, to those that have more wide-

\section{W.J. McGuire}

Department of Earth Sciences, UCL Hazard Centre, University College London,

London WC1E 6BT, UK

e-mail:w.mcguire@ucl.ac.uk

\section{C.J. Fearnley $(\square)$}

Department of Science and Technology, University College London, Gower Street, London WC1E 6BT, UK

e-mail: c.fearnley@ucl.ac.uk spread ramifications, most especially tephra and the manifold consequences of extreme volcanic events.

To date, little consideration has been given to the hazard arising from the ejection of ballistic material from explosive vents, perhaps because the numbers of people exposed tend to be small and death and injury tolls have been limited. As Fitzgerald et al. observes in "The Communication and Risk Management of Volcanic Ballistic Hazards", casualties of ballistic events are largely restricted to tourists, hikers, locals and volcanologists, who visit and linger in the immediate vicinity of active vents. Nonetheless, notes the author, ballistic ejecta can be hurled to distances of several kilometres from source, and is capable of causing significant damage to property and infrastructure within range. Fitzgerald reviews the current state of thinking on the ballistic hazard and the methodologies used to communicate and manage associated risk, and addresses the potential for developing new tools and management approaches.

Closely linked to ballistic hazard is the general threat to life presented by areas of active hydrothermal activity, principally because explosions at hydrothermal vents often generate ballistic ejecta. The hazards characterising hydrothermal fields are, however, more diverse, and include geysers, fumaroles and pools of boiling mud and water. In "Active Hydrothermal Features as Tourist Attractions", Erfurt-Cooper highlights the fact that such fields constitute environments, the unpredictability and potential 
hostility of which are rarely fully appreciated by visitors. This, the author observes, is making the management of hydrothermal hazards increasingly problematic as tourist numbers increase. Erfurt-Cooper focuses attention, in particular, on hydrothermal areas that are also significant tourist attractions; evaluating potential hazards in the context of reducing accidents and limiting injuries to visitors.

The destructive and lethal potential of pyroclastic density currents (PDCs) is well known, as are the issues that make successful mitigation problematic; high velocities; extreme temperatures; sediment and debris load; and mobility. In "Mapping Hazard Zones, Rapid Warning Communication and Understanding Communities: Primary Ways to Mitigate Pyroclastic Flow Hazard", Lavigne et al. discuss how communication of a hazard that has, effectively, no warning time, might best be approached. They note that, given the properties of PDCs, the only useful approach is a precautionary one centred around building understanding in at-risk communities, hazard zonation, and rapid and effective warning. Challenges abound, however, which Lavigne and his colleagues analyse, concluding that efficient dissemination of information and an improved understanding of how at-risk communities are likely to respond, are key to mitigating the effects of PDCs on populated areas close to active volcanoes.

Volcanic ash and gases provide the means whereby the reach of an erupting volcano may be extended over many thousands of square kilometres and, in the most extreme cases, across the globe. The communication demands of such spatially extensive hazards are very different from those relating to hazards confined to a volcano and its immediate environs. As Stewart et al., note in "Communication Demands of Volcanic Ashfall Events", forecasting when, where and how much ash will fall during an eruption, constitutes a major challenge that requires a suite of communication strategies rather than a single solution. Stewart and her co-authors examine the factors that contribute to the complex 'communication environment' that characterises ashfall hazard and review the various communication tools and methodologies available across a range of sectors, including public health, agriculture and critical infrastructure. They also highlight the peculiar challenges presented by long duration, ash-producing, eruptions, and during the clean-up and recovery following ashfall events.

The major threat that widespread clouds of volcanic ash present to the aviation industry, has been highlighted in the last six years by disruptive eruptions at Eyjafjallajökull (2010) and Grimsvötn (2011) - both in Iceland - and the Chilean volcanoes, Puyehue-cordón Caulle (2011) and Calbuco (2011). In addition, there have been numerous examples of encounters between individual aircraft and ash clouds in the vicinity of erupting volcanoes that are close to flight paths. In "Volcanic Ash and AviationThe Challenges of Real-Time, Global Communication of a Natural Hazard", Peter Lechner et al., focus on the range of issues that arise due to interactions between ash and aircraft, noting that informing aircraft in-flight of the exact distribution of potentially dangerous ash clouds in the vicinity remains a challenge. The authors present a picture of how the aviation industry currently deals with ash clouds, within the framework of the International Airways Volcano Watch (IAVW), observing that management of ash cloud events has improved considerably since the 1980s. Lechner and his co-authors highlight the import role international collaboration has played in developing a global warning system, but recognise that there is still work to do, notably in improving communication prior to, and at the onset of, an ash-producing event.

In the manner of ash, volcanic gases can have serious consequences close to a volcano, but also half a world away. As Edmonds et al., note in "Volcanic Gases: Silent Killers", proximally, the effects may include asphyxiation, respiratory diseases and skin burns while, further afield, widespread famine may result from the climate-modifying ramifications of sulphate aerosols injected into the stratosphere. The authors identify a number of key challenges related to tackling the volcanic gas threat, notably difficulties 
in monitoring gas concentrations and communicating the results to those who need to know, and improving understanding of the gas risk amongst at-risk populations. Edmonds and her colleagues examine a range of scenarios, including carbon dioxide release from lake overturn events and the large-scale loading of the troposphere and stratosphere with volcanic sulphate. In the latter context, there is a particular focus on the 1783 Laki (Iceland) eruption, and its impact on climate and health across the UK and Europe, and how a future eruption of this type might be managed.

It seems fitting that, in the final chapter of Part One, "Imagining the Unimaginable: Communicating Extreme Volcanic Risk" Donovan and Oppenheimer consider how we might tackle an eruption large enough to qualify as a global geophysical event. Such eruptions recognise no boundaries and have the potential to impact in some way upon many, if not all, nation states. As such, the problems of communicating the associated hazards are unique. Donovan and Oppenheimer focus on communication both prior to and during such an eruption. While noting that no volcano erupts on such a scale without warning signs, the authors caution that great uncertainties in likelihood, timing, nature and magnitude of extreme volcanic events would, nonetheless, provide a major challenge to effective communication of the hazard and risk, as would problems arising in seeking to provide clear messages beyond the borders of the country that hosts the volcano. Donovan and Oppenheimer also highlight the need to ensure that communication strategies developed prior to the start of the eruption are robust enough to survive through the course of the eruptive event, so as to provide for reporting of the status of the eruption, the degree and nature of damage and disruption, and any logistical requirements.
Open Access This chapter is distributed under the terms of the Creative Commons Attribution 4.0 International License (http://creativecommons.org/licenses/by/4.0/), which permits use, duplication, adaptation, distribution and reproduction in any medium or format, as long as you give appropriate credit to the original author(s) and the source, a link is provided to the Creative Commons license and indicate if changes were made.
The images or other third party material in this chapter are included in the chapter's Creative Commons license, unless indicated otherwise in a credit line to the material. If material is not included in the chapter's Creative Commons license and your intended use is not permitted by statutory regulation or exceeds the permitted use, you will need to obtain permission directly from the copyright holder. 